\title{
Adaptation and qualitative evaluation of encounter decision aids in breast cancer care
}

\author{
Pola Hahlweg ${ }^{1} \oplus \cdot$ Isabell Witzel $^{2} \cdot$ Volkmar Müller $^{2} \cdot$ Glyn Elwyn $^{3} \cdot$ Marie-Anne Durand $^{3} \cdot$ Isabelle Scholl $^{1}$
}

Received: 4 July 2018 / Accepted: 18 December 2018 / Published online: 16 January 2019

(c) The Author(s) 2019

\begin{abstract}
Purpose Shared decision-making is currently not widely implemented in breast cancer care. Encounter decision aids support shared decision-making by helping patients and physicians compare treatment options. So far, little was known about adaptation needs for translated encounter decision aids, and encounter decision aids for breast cancer treatments were not available in Germany. This study aimed to adapt and evaluate the implementation of two encounter decision aids on breast cancer treatments in routine care.

Methods We conducted a multi-phase qualitative study: (1) translation of two breast cancer Option Grid ${ }^{\mathrm{TM}}$ decision aids; comparison to national clinical standards; cognitive interviews to test patients' understanding; (2) focus groups to assess acceptability; (3) testing in routine care using participant observation. Data were analysed using qualitative content analysis. Results Physicians and patients reacted positively to the idea of encounter decision aids, and reported being interested in using them; patients were most receptive. Several adaptation cycles were necessary. Uncertainty about feasibility of using encounter decision aids in clinical settings was the main physician-reported barrier. During real-world testing $(N=77$ encounters), physicians used encounter decision aids in one-third of potentially relevant encounters. However, they did not use the encounter decision aids to stimulate dialogue, which is contrary to their original scope and purpose.

Conclusions The idea of using encounter decision aids was welcomed, but more by patients than by physicians. Adaptation was a complex process and required resources. Clinicians did not follow suggested strategies for using encounter decision aids. Our study indicates that production of encounter decision aids alone will not lead to successful implementation, and has to be accompanied by training of health care providers.
\end{abstract}

Keywords Breast cancer $\cdot$ Shared decision-making $\cdot$ Encounter decision aids $\cdot$ Option Grid ${ }^{\mathrm{TM}}$ decision aids $\cdot$ Cross-cultural adaptation

\begin{tabular}{lll} 
& \multicolumn{2}{l}{ Abbreviations } \\
& BCT & Breast conserving therapy \\
\hline Electronic supplementary material The online version of this & DA & Decision aid \\
article (https://doi.org/10.1007/s00404-018-5035-7) contains & EDA & Encounter decision aid \\
supplementary material, which is available to authorized users. & FAQ & Frequently asked questions \\
\hline $\begin{array}{l}\text { Pola Hahlweg } \\
\text { p.hahlweg@uke.de }\end{array}$ & GE & Glyn Elwyn \\
& IPDAS & International Patient Decision Aids Standards \\
Department of Medical Psychology, University & IS & Isabelle Scholl \\
Medical Center Hamburg-Eppendorf, Martinistraße 52, & IW & Isabelle Witzel \\
20246 Hamburg, Germany & MAD & Marie-Anne Durand \\
Department of Gynecology, University Medical Center & N & Sample size \\
Hamburg-Eppendorf, Martinistraße 52, 20246 Hamburg, & PH & Pola Hahlweg \\
Germany & SD & Standard deviation \\
The Dartmouth Institute for Health Policy and Clinical & SDM & Shared decision-making \\
Practice, Dartmouth College, Level 5, Williamson & VM & Volkmar Müller \\
Transtion & WF & Wiebke Frerichs
\end{tabular}




\section{Introduction}

In breast cancer treatment, patients and physicians have to make several decisions regarding treatment options that might considerably affect patients' quality of life and other person-centred health outcomes. With many new emerging treatment options, this process has become more complex and challenging for patients and physicians over the last years. It is, therefore, important to take patients' preferences and values into account $[1,2]$. Strategies to support these challenging decision-making processes are needed. Studies showed that the majority of patients wants to be well informed and participate in decision-making processes [3-7].

Patient participation can be achieved through shared decision-making (SDM). SDM is an interactional process between patient and physician [1]. The aim is for both parties to be actively involved and come to a shared and informed treatment decision based on the available clinical evidence and the patient's individual preferences and values [8]. Within this process, the physician supports the patient to weigh the benefits and risks as well as possible consequences of different treatment options [9]. Since patients and physicians appraise the quality of different treatment options differently [10], it is important to encourage a dialogue and come to a shared understanding of what the best option for the individual patient is.

Routine cancer care often does not meet patients' preferences optimally $[11,12]$. Decision aids (DAs) are supporting materials that facilitate the involvement of patients in decision-making processes by depicting different treatment options with their respective benefits and risks [13]. Many DAs (e.g. brochures or videos) contain detailed information for patients to read before or after the clinical encounter. Recently, short DAs (so-called encounter decision aids, EDAs), which can be used during the clinical encounter, were developed and evaluated [14, 15]. EDAs have shown to support the implementation of SDM [16-18]. A Cochrane review of 105 studies involving a total of 31,043 participants showed positive effects of DAs on several outcomes, e.g. DAs improved the correct perception of benefits and risks of different options, reduced decisional conflict, and increased active involvement of patients [14]. However, the length of many DAs hinders the implementation in routine practice [19]. Short EDAs to support SDM during the clinical encounter seem more promising for changing the dialogue [20,21]. EDAs are currently lacking in many languages (e.g. German) [22], and little is known about needs for cross-cultural adaptation of translated EDAs.

Thus, this study aimed to adapt and pilot test the translations of two EDAs for breast cancer treatment: (a) surgical options for breast cancer and (b) options for breast reconstruction after mastectomy. This included (1) the translation and cross-cultural adaptation of the EDAs for breast cancer treatment, (2) the evaluation of the patients' and physicians' acceptance of the translated EDAs, and (3) the evaluation of the EDAs' feasibility in routine care.

\section{Methods}

\section{Study design}

We conducted a qualitative cross-sectional study. In phase 1 we translated and adapted two English EDAs into German. Pilot testing included an assessment of acceptance (phase 2 ), and testing in the real-world setting (phase 3). We followed the COREQ reporting guideline (cp. supplementary material) [23].

\section{Option Grid ${ }^{\mathrm{Tm}} \mathrm{DAs}$}

The EDAs used in this study are Option Grid DAs. Those are one-page documents consisting of a table filled with the most important information on different treatment options. Each line in the tables stands for one frequently asked question (FAQ) regarding the topic. In the columns, the answers for each option are given (cp. supplementary material). Physicians can use those tables during the clinical encounter to explain the different treatment options, facilitate comparison, and come to a shared decision. The Option Grid Collaborative, a consortium of researchers, clinicians, and patient representatives from the US and Great Britain, developed a multitude of such Option Grid DAs [24, 25].

\section{Setting and subjects}

We cooperated with a certified comprehensive breast cancer centre at a university hospital in Germany. Inclusion criteria for patients participating in phases 1 and 2 (interviews and focus groups) were as follows: (1) diagnosed with breast cancer and not currently facing decisions about surgery or breast reconstruction, (2) age 18 years and older. Exclusion criteria were insufficient knowledge of German language or severe cognitive impairment. The inclusion criterion for physicians participating in phase 2 (focus groups and interviews) was a specialization in breast cancer care. Phase 3 (participant observations) took place at the breast centre during consultation hours at the outpatient clinic.

\section{Recruitment}

Prior to participation, we informed participants about the study and obtained written informed consent. 
We used purposive sampling aiming to include participants with diverse demographic characteristics in phases 1 and 2, convenience sampling in phase 3 . We recruited patients for interviews and focus groups face-to-face in collaboration with staff at the breast centre and with a patient organization. Physicians participating in focus groups and interviews were recruited through collaboration partners and email inquiries to various breast cancer facilities in the metropolitan region of Hamburg. We offered participants in phases 1 and 2 a compensation fee of 25 Euros. Patients participating during participant observations were recruited face-to-face at the breast centre by study team members.

\section{Data collection}

Participants in phases 1 and 2 completed a short demographic survey.

\section{Phase 1: translation and adaptation}

The translation procedure was derived from the TRAPD protocol $[26,27]$. Necessary adaptations to German clinical standards were discussed with breast cancer specialists in our multidisciplinary team (IW, VM). National guidelines [28] and current evidence-based developments were taken into account. Patient comprehensibility was tested in cognitive interviews at the university hospital (conducted by $\mathrm{PH}$, female psychologist experienced in interviewing) with $N=9$ patients [29]. Cognitive interviews followed a guideline developed within this study, lasted about $1 \mathrm{~h}$, and were audio-recorded. After adaptations, the final translated versions of the Option Grid DAs were mailed to $N=10$ patients accompanied by a short survey asking if the adaptation led to improvements, and if final versions were well understandable.

\section{Phase 2: assessment of acceptance}

Final German versions of the Option Grid DAs were tested, based on the recommendations of the International Patient Decision Aids Standards (IPDAS) Collaboration, which developed internationally accepted standards for DAs [30].

First, we tested acceptance of the EDAs through focus groups and interviews with patients and physicians specialized in breast cancer (phase 2, [30]). The planned sample size was $16-20$ for both physicians and patients or until data saturation. Focus groups lasted $120 \mathrm{~min}$, took place at the university hospital, followed a guideline developed within the study and were chaired by IS and PH, two female psychologists experienced in administering focus groups. We offered physicians and patients, unable to participate in a focus group, individual interviews instead (conducted by $\mathrm{PH}$ ). Focus groups and interviews were audio-recorded.

\section{Phase 3: testing in the real-world setting}

Prior to participant observations in the real-world setting (phase 3, [30]), physicians working at the breast centre received a 60-min group training in administering the EDAs. This training consisted of general information on SDM and EDAs, a guideline for the use of Option Grid DAs, and an example video. Physicians were asked to use the Option Grid DAs when consulting with patients facing one of the relevant treatment decisions. Feasibility of using the German Option Grid DAs was assessed at the breast centre over a period of 4 weeks. During the first week, we sought to observe as many clinical encounters as possible to gain an overview; for the following 3 weeks, we pre-selected potentially relevant encounters in collaboration with staff at the breast centre to save resources. One researcher $(\mathrm{PH}$, female psychologist experienced in participant observation [31, 32]) carried out the observations. We recorded observations on a pre-structured form (cp. supplementary material). The observer elaborated barriers for the use of the EDAs either by explicitly asking the physicians, or by drawing conclusions about potential barriers from the observed situation.

\section{Data analysis}

First, one person (PH) cumulated all comments and suggestions from the audio-recordings of the cognitive interviews into one document. Second, the relevance of all comments and suggestions was discussed in the study group (IS, $\mathrm{PH}$ ). Taking into account the physician feedback (given by IW, VM) and the results of the cognitive interviews with patients, final German versions of the two EDAs were established after consultation with the developers (GE, MAD).

Audio-recordings were transcribed verbatim; field notes of participant observations were digitalized. Transcripts were not returned to participants for approval. We analysed the anonymized qualitative data following the principles of Mayring's qualitative content analysis, a systematic, ruleguided approach to analyse text by categorizing relevant themes and sub-themes [33]. Two members of the research team (PH, IS) carried out the analyses using MAXQDA software (version 10, VERBI GmbH, Berlin, Germany).

\section{Results}

\section{Phase 1: translation and adaptation}

The translation of the Option Grid DAs with two translators (PH; WF, cp. acknowledgements) and one reviewer (IS) was feasible. The adaptation process was more extensive than expected, because several feedback circles between the core executive study team, breast care 
specialists, and developers at the Option Grid collaborative were necessary to establish agreement on the prefinal German versions. Physicians voiced the necessity to include new clinical evidence into the DAs (e.g. regarding survival rates after breast conserving therapy or mastectomy [34]), and make minor additions in content. It was also necessary to adapt, so the content would match the current state of breast cancer care delivery in Germany.

Compare Table 1 for demographic characteristics of patients participating in cognitive interviews. Cognitive interviews with patients showed overall good understanding of the Option Grid DAs. Only a few changes in the DAs were made to reflect the results of the cognitive interviews and additional results from focus group discussions (e.g. wording of certain medical terms, order of FAQs, and clarification of minor logical incongruities). Again, the core executive study team and the developers at the Option Grid collaborative discussed and agreed on the final German versions.
Eight of ten patients, who received the final versions of the DAs by mail, responded. They indicated that the EDAs were well $(N=4)$ to very well $(N=4)$ understandable. Seven of the eight patients indicated improvement of the EDAs during the adaptation process.

Compare supplementary material for the final German versions of the Option Grid DAs.

\section{Phase 2: acceptance of the German Option Grid DAs}

Acceptance was assessed in a sample of $N=13$ patients (two focus groups, three interviews) and $N=13$ physicians (one focus group, seven interviews). Tables 1 and 2 show demographic characteristics of patients and physicians.

Physicians and especially patients valued the idea of Option Grid DAs and expressed interest in using them. They thought of the EDAs as supporting tools for patients and physicians during and after the clinical encounter. One physician said, "In my opinion it [the EDA] is clearly structured

Table 1 Demographic and clinical characteristics of patients in phases 1 and 2

\begin{tabular}{|c|c|c|c|c|}
\hline & \multicolumn{2}{|c|}{ Phase 1: cognitive interviews with patients $(N=9)$} & \multicolumn{2}{|c|}{$\begin{array}{l}\text { Phase } 2 \text { : focus groups and interviews } \\
\text { with patients }\left(N=13^{\mathrm{a}}\right)\end{array}$} \\
\hline & Mean (SD) & Range & Mean (SD) & Range \\
\hline \multirow[t]{2}{*}{ Age (in years) } & $53.3(11.0)$ & $32-66$ & $57.2(11.1)$ & $30-71$ \\
\hline & $N$ & $\%$ & $N$ & $\%$ \\
\hline Sex: Female & 9 & 100 & 13 & 100 \\
\hline \multicolumn{5}{|l|}{ Mother tongue } \\
\hline German & 8 & 89 & 12 & 92 \\
\hline Other & 1 & 11 & 0 & 0 \\
\hline Missing & 0 & 0 & 1 & 8 \\
\hline \multicolumn{5}{|l|}{ Level of education } \\
\hline Low $^{\mathrm{b}}$ & 2 & 22 & 0 & 0 \\
\hline Intermediate $^{c}$ & 3 & 33 & 5 & 38 \\
\hline $\operatorname{High}^{\mathrm{d}}$ & 4 & 44 & 8 & 62 \\
\hline \multicolumn{5}{|l|}{ Surgical procedure } \\
\hline Lumpectomy & 3 & 33 & $9^{e}$ & $69^{e}$ \\
\hline Mastectomy & 5 & 56 & $6^{\mathrm{e}}$ & $46^{\mathrm{e}}$ \\
\hline Missing & 1 & 11 & & \\
\hline Reconstruction & 3 & 33 & 3 & 23 \\
\hline \multicolumn{5}{|l|}{ Additional treatments } \\
\hline Chemotherapy & 6 & 67 & 9 & 69 \\
\hline Radiation & 6 & 67 & 8 & 62 \\
\hline Anti-hormonal therapy & 4 & 44 & 4 & 31 \\
\hline
\end{tabular}

$N$ sample size, $S D$ standard deviation, $B C T$ breast conserving therapy

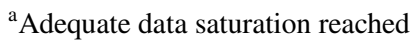

${ }^{\text {b }}$ Years of education completed $\leq 9$

${ }^{\mathrm{c}}$ Years of education completed $10-12$

${ }^{\mathrm{d}}$ Years of education completed $\geq 13$

${ }^{\mathrm{e}}$ Two cases indicated lumpectomy and mastectomy 
Table 2 Demographic characteristics of breast cancer specialists in phase 2

Phase 2: focus groups and interviews with physicians $\left(N=13^{\mathrm{a}}\right)$

\begin{tabular}{lll}
\hline & Mean (SD) & Range \\
\hline Age (in years) & $46.4(10.5)$ & $31-60$ \\
Work experience (in years) & $17.4(9.4)$ & $4-35$ \\
\hline & $N$ & 54 \\
\hline Sex: Female & 7 & 62 \\
Work setting & & 38 \\
Breast centre & 8 & 5 \\
Private practice & 5 & \\
\hline
\end{tabular}

$N$ sample size, $S D$ standard deviation

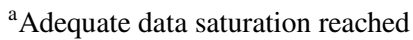

and I think it is very helpful for patients; especially that they can look at it afterwards [i.e. after the clinical encounter]". A patient described how she felt during initial diagnosis as follows, "I could not concentrate. I could not absorb any information. I thought I had understood everything very quickly. At home everything had vanished [...] and that is why I think this slip of paper [the EDA] is good". Some physicians and few patients were more sceptical regarding the EDAs. One physician said, "I think that one can also cause information overload for patients with this sheet".

On the one hand, most participants thought that Option Grid DAs are probably not suitable for all patients, because of, e.g. diverse personality traits and cognitive abilities. On the other hand, several participants indicated that all patients should be offered the DAs. Physicians emphasized that they do not feel comfortable with handing out EDAs to patients prior to a first face-to-face encounter.
We found six categories of influencing factors for the acceptance of the Option Grid DAs, which are described in Table 3.

\section{Phase 3: feasibility assessment}

Eighty-nine of 103 invited patients $(86.4 \%)$ consented to participate. Over a period of 4 weeks, we observed clinical encounters of 66 of those 89 distinct patients (74.2\%). In 11 of the observed cases, we additionally observed a follow-up visit scheduled within the 4-week-timeframe. This led to $N=77$ clinical encounters included in the analyses. Visits lasted between 3 and 65 min (mean 18.1, SD 11.9). In 29 of the 77 encounters (37.7\%), one or more significant others of the patient were present. Most often this was a partner/spouse (15 out of 77 visits, $19.5 \%$ ), friend ( 7 out of 77 visits, $9.1 \%$ ), parent (4 out of 77 visits, $5.2 \%$ ), or

Table 3 Factors influencing the acceptance of the Option Grid DAs

Influencing factors Description

\section{Factors increasing acceptance}

Helpful during the clinical encounter

Helpful after the clinical encounter

\section{Factors with mixed feedback}

Factors regarding the EDA itself

Emotional aspects

\section{Factors decreasing acceptance}

Factors regarding feasibility
The EDAs were thought to stimulate questions, and support the clinical encounter

Patients could take the EDAs home

This included the information on the EDAs, the structure of the EDAs, linguistic aspects, and the balance between offering detailed information and being short

Especially patients emphasized that the DAs could reduce anxiety. Some physicians voiced that the DAs could unsettle and overburden patients

This included prerequisites for using the EDAs (e.g. EDAs need to be embedded in clinical encounter and not stand alone; use of the EDA should be introduced as an offer not a must do). Structural barriers were mentioned (e.g. time pressure, one encounter including communication of the diagnosis and treatment decision). The right point in time for the administration of the EDAs was controversially discussed

Questioning the preference sensitivity of Physicians questioned the nature of the decisions as preference-sensitive the decisions depicted in the two EDAs 
grown-up child (4 out of 77 visits, 5.2\%). For descriptive statistics on the current diagnoses, see Table 4.

Thirty-three $(42.9 \%)$ of the 77 clinical encounters focused on surgery planning (breast surgery and/or reconstruction). In twelve of those 33 potentially relevant visits (36.4\%), physicians broached the issue of the Option Grid DAs. In nine of those twelve visits, one or both of the EDAs were used (twice both EDAs, five times surgical options EDA, twice breast reconstruction EDA). In the other three of those twelve encounters, physicians referred to the EDAs used in the prior clinical encounter, but did not look at the EDAs again. After three additional encounters, where physicians did not broach the issue of Option Grid DAs with the patients, physicians mentioned to the observer that using the tool would have been useful with that patient.

If Option Grid DAs were used, physicians explained the format shortly. A detailed elaboration of different options on the EDA was not observed. Patients only had little time to familiarize themselves with the EDAs during the clinical encounters. In one encounter, a family-member read the EDA during the patient's physical examination and asked the physician questions afterwards. Apart from this encounter, patients only briefly looked at the EDA during the encounter or did not look at it at all. In seven of the nine cases, the patient took the EDA with her after the clinical encounter.

Barriers to the use of EDAs were clinical reasons (e.g. physician did not consider decision preference-sensitive), structural aspects (e.g. lack of time), and individual patient characteristics (e.g. language barriers). Facilitators for the use of EDAs were (a) decision-making process being spread out over more than one clinical encounter, (b) patient giving positive feedback about the EDAs and therewith reinforcing the use, and (c) patient being overwhelmed by only verbal information.

Table 4 Current state of disease

\begin{tabular}{lcc}
\hline Disease & Frequency & $\%$ \\
\hline Primary breast cancer & 29 & 37.7 \\
Metastatic breast cancer & 15 & 19.5 \\
Suspected breast cancer & 12 & 15.6 \\
DCIS & 6 & 7.8 \\
Recurrent breast cancer & 4 & 5.2 \\
With a history of breast cancer & 4 & 5.2 \\
Other $^{\text {a }}$ & 7 & 9.1 \\
\hline
\end{tabular}

${ }^{\mathrm{a}}$ E.g. genetic mutation, cyst of the breast, micro-calcifications

\section{Discussion}

Our results suggest that physicians and patients value the idea of EDAs and show interest in using them during and after clinical encounters. However, we needed several cycles of adaptation to reach adequate acceptance by German physicians and patients. Several physicians questioned the feasibility of using EDAs in breast cancer care. Testing in routine care showed that physicians used Option Grid DAs in one-third of potentially relevant encounters. However, if Option Grid DAs were used, they were not discussed in depth during the clinical encounter.

This is the first study of its kind and therewith adds important insight for following research on EDAs. The good acceptance we found for the Option Grid DAs provides a basis for additional research on short EDAs. However, this is a pilot study. The sample size suffices for this kind of study (i.e. qualitative study aiming to gain insight into attitudes and processes). This lays ground for larger studies assessing effectiveness and feasibility of EDAs to produce results with better generalizability in the future. We cannot appraise within this study, how much the presence of the observer motivated physicians to use the EDAs. Also, if patients engaged in reading the EDA after the clinical encounter was not assessed within this study.

This study emphasizes the importance of thorough adaptation of translated DAs. We found that the discussion of discrepancies with different stakeholders of the target population and the developers of the original EDAs was a fruitful albeit time-intensive process. To pay attention to those adaptation needs is the first step towards generating a well-accepted tool.

The main challenges for the use of Option Grid DAs were doubts about the feasibility of the EDAs in routine cancer care. Other studies also found that medical staff appraises the incorporation of DAs in existing clinical routines as challenging $[35,36]$ and that DAs are not sufficiently implemented in routine care [19].

A current study on the use of Option Grid DAs for several treatment decisions showed that physicians ask for more training and feedback on the use of Option Grid DAs [20]. In our study, physicians did not discuss the options on the DAs during the clinical encounter. Possibly, our short physician training was not sufficient to enable physicians to elaborate on the EDAs during the encounter. More training and feedback might have strengthened the use of the tools. This is in line with implementation science that suggests that behaviour change is best achieved through a combination of initial training and ongoing support [37].

The next step in research and practice could be to assess methods to support the implementation of the available adapted EDAs. This would be especially valuable since 
new studies showed that the use of EDAs supports the implementation of SDM [16, 17]. Barriers reported in this study such as uncertainty about the right moment to administer the DAs, time pressure, or the questioning of preference-sensitivity need to be addressed in training and support efforts. Besides practical and structural barriers, physicians' attitude towards SDM is essential for EDAs to be successful.

At the same time, DAs are only one way to support SDM. Légaré and colleagues emphasized that we need interventions that target different aspects of the decisionmaking process to successfully foster the implementation of SDM in routine care [38]. It is extremely important that implementation programs are multi-faceted and based on implementation science. The cluster randomized implementation study that is currently conducted at the University Medical Center Hamburg-Eppendorf is one example of such a multi-faceted implementation program [39].

\section{Conclusion}

This study provides German versions of two EDAs for breast cancer treatment that have been thoroughly adapted with attention to cross-cultural factors. It was shown that after adaptation acceptance is promising overall. However, the implementation of EDAs needs to be facilitated. The next step will be to find ways to implement EDAs in routine breast cancer care, and therewith support the implementation of SDM.

Acknowledgements We thank Janine Topp and Eva Christalle for their support as student researchers. We thank Wiebke Frerichs (WF) for her support with the translation of the DAs, and the entire team of the Breast Cancer Center at the University Medical Center HamburgEppendorf for their support throughout data collection. We also thank the Frauenselbsthilfe nach Krebs (self-help group for breast cancer patients) for their cooperation during recruitment, and all patients and physicians who participated in the study.

Author contributions $\mathrm{PH}$ : project development, data collection and management, data analysis, and manuscript writing/editing. IW: data collection and manuscript writing/editing. VM: data collection and manuscript writing/editing. GE: project development, data analysis and manuscript writing/editing. MAD: project development, data analysis and manuscript writing/editing. IS: project development, data collection and management, data analysis, and manuscript writing/editing. All authors gave final approval of the version to be published.

Funding This work was supported by research funding through faculty resources of the University Medical Center Hamburg-Eppendorf (German: Forschungsförderfonds der Medizinischen Fakultät der Universität Hamburg, FFM; Grant number: NWF 15_10). The sponsors were not involved in the study design; in the collection, analysis and interpretation of data; nor in the decision to submit the paper for publication.
Availability of data and materials The dataset supporting the conclusions of this article is available upon request for researchers after consultation with the corresponding author and the responsible Ethics Committee. Please contact the corresponding author, Pola Hahlweg (Email: p.hahlweg@uke.de), if you wish to request the data set.

\section{Compliance with ethical standards}

Conflict of interest PH's institution received the grant from research funding through faculty resources of the University Medical Center Hamburg-Eppendorf (German: Forschungsförderfonds der Medizinischen Fakultät der Universität Hamburg, FFM) for the study at hand (cp. funding). $\mathrm{PH}$ gave one scientific presentation on shared decisionmaking during a lunch symposium, for which she received compensation and travel compensation from GlaxoSmithKline GmbH in 2018. IW and VM declare no conflicts of interest. GE is the director of \&think LLC which owns the registered trademark for Option Grid ${ }^{\mathrm{TM}}$ patient decision aids. GE currently provides consultancy in the domain of shared decision-making and patient decision aids to Access Community Health Network, Chicago (Federally Qualified Medical Centers) and EBSCO Health Option Grid ${ }^{\mathrm{TM}}$ patient decision aids. In the past, GE was a consultant to Emmi Solutions LLC (development of Option Grid ${ }^{\mathrm{TM}}$ DAs), to the National Quality Forum (certification of decision support tools), to the Washington State Health Department (certification of decision support tools), and to SciMentum LLC, Amsterdam (workshops for SDM). GE receives royalties from Oxford University Press and Radcliff Press, because he edited and published books that provide royalties on sales by the publishers. The books include Shared Decision Making (Oxford University Press) and Groups. GE initiated the Option Grid Collaborative, tools that are hosted on a website managed by Dartmouth College (http://optiongrid.org/). Existing Option Grids hosted at this website are freely available until the tools have expired. He owns copyright in measures of SDM and care integration, namely CollaboRATE, IntegRATE, and Observer OPTION. These measures are freely available for use. MAD has contributed to the development of Option Grid ${ }^{\mathrm{TM}}$ patient decision aids, which are licensed to EBSCO Health. She receives consulting income from EBSCO Health, and may receive royalties in the future. MAD is a consultant to ACCESS Community Health Network. MAD is one of the founding members of the Option Grid Collaborative. IS's institution received the grant from research funding through faculty resources of the University Medical Center Hamburg-Eppendorf (German: Forschungsförderfonds der Medizinischen Fakultät der Universität Hamburg, FFM) for the study at hand (cp. funding). IS conducted one physician training in shared decision-making for which she received travel compensation from Mundipharma GmbH in 2015.

Ethics approval and consent to participate All procedures performed in studies involving human participants were in accordance with the ethical standards of the institutional and/or national research committee and with the 1964 Helsinki declaration and its later amendments or comparable ethical standards. The study was approved by the Ethics Committee of the Medical Association Hamburg (Germany). Informed consent was obtained from all individual participants included in the study.

Open Access This article is distributed under the terms of the Creative Commons Attribution 4.0 International License (http://creativeco mmons.org/licenses/by/4.0/), which permits unrestricted use, distribution, and reproduction in any medium, provided you give appropriate credit to the original author(s) and the source, provide a link to the Creative Commons license, and indicate if changes were made. 


\section{References}

1. Charles C, Gafni A, Whelan T (1997) Shared decision-making in the medical encounter: what does it mean? (or it takes at least two to tango). Soc Sci Med 44(5):681-692. https://doi.org/10.1016/ S0277-9536(96)00221-3

2. Whitney SN (2003) A new model of medical decisions: exploring the limits of shared decision making. Med Decis Mak 23(4):275280. https://doi.org/10.1177/0272989x03256006

3. Chewning B, Bylund CL, Shah B, Arora NK, Gueguen JA, Makoul G (2012) Patient preferences for shared decisions: a systematic review. Patient Educ Couns 86(1):9-18. https://doi.org/10.1016/j. pec.2011.02.004

4. Jenkins V, Fallowfield L, Saul J (2001) Information needs of patients with cancer: results from a large study in UK cancer centres. Br J Cancer 84(1):48-51. https://doi.org/10.1054/ bjoc. 2000.1573

5. Vogel BA, Helmes AW, Hasenburg A (2008) Concordance between patients' desired and actual decision-making roles in breast cancer care. Psychooncology 17(2):182-189. https://doi. org/10.1002/pon.1215

6. Hamann J, Neuner B, Kasper J, Vodermaier A, Loh A, Deinzer A, Heesen C, Kissling W, Busch R, Schmieder R, Spies C, Caspari C, Härter M (2007) Participation preferences of patients with acute and chronic conditions. Health Expect 10(4):358-363. https://doi. org/10.1111/j.1369-7625.2007.00458.x

7. Schuler M, Schildmann J, Trautmann F, Hentschel L, Hornemann B, Rentsch A, Ehninger G, Schmitt J (2017) Cancer patients' control preferences in decision making and associations with patient-reported outcomes: a prospective study in an outpatient cancer center. Support Care Cancer 25(9):2753-2760. https://doi. org/10.1007/s00520-017-3686-8

8. Härter M, Moumjid N, Cornuz J, Elwyn G, van der Weijden T (2017) Shared decision making in 2017: international accomplishments in policy, research and implementation. Zeitschrift für Evidenz, Fortbildung und Qualität im Gesundheitswesen 123:1-5. https://doi.org/10.1016/j.zefq.2017.05.024

9. Elwyn G, Laitner S, Coulter A, Walker E, Watson P, Thomson R (2010) Implementing shared decision making in the NHS. BMJ 341:971-975. https://doi.org/10.1136/bmj.c5146

10. Thiel FC, Schrauder MG, Fasching PA, Löhberg CR, Bani MR, Häberle L, Tänzer T, Radosavac D, Scharl A, Bauerfeind I, Gesslein J, Schulte H, Overbeck-Schulte B, Beckmann MW, Lux MP (2012) Shared decision-making in breast cancer: discrepancy between the treatment efficacy required by patients and by physicians. Breast Cancer Res Treat 135(3):811-820. https:// doi.org/10.1007/s10549-012-2218-y

11. Brom L, Hopmans W, Pasman HR, Timmermans D, Widdershoven G, Onwuteaka-Philipsen B (2014) Congruence between patients' preferred and perceived participation in medical decision-making: a review of the literature. BMC Med Inform Decis Mak 14:25. https://doi.org/10.1186/1472-6947-14-25

12. Puts MT, Papoutsis A, Springall E, Tourangeau AE (2012) A systematic review of unmet needs of newly diagnosed older cancer patients undergoing active cancer treatment. Support Care Cancer 20(7):1377-1394. https://doi.org/10.1007/s00520-012-1450-7

13. Elwyn G, Frosch D, Volandes AE, Edwards A, Montori VM (2010) Investing in deliberation: a definition and classification of decision support interventions for people facing difficult health decisions. Med Decis Mak 30(6):701-711. https://doi. org/10.1177/0272989x10386231

14. Stacey D, Légaré F, Lewis K, Barry MJ, Bennett CL, Eden KB, Holmes-Rovner M, Llewellyn-Thomas H, Lyddiatt A, Thomson R, Trevena L (2017) Decision aids for people facing health treatment or screening decisions. Cochrane Database Syst Rev 4:CD001431. https://doi.org/10.1002/14651858.cd001431.pub5

15. Breslin M, Mullan RJ, Montori VM (2008) The design of a decision aid about diabetes medications for use during the consultation with patients with type 2 diabetes. Patient Educ Couns 73(3):465472. https://doi.org/10.1016/j.pec.2008.07.024

16. Elwyn G, Pickles T, Edwards A, Kinsey K, Brain K, Newcombe RG, Firth J, Marrin K, Nye A, Wood F (2016) Supporting shared decision making using an Option Grid for osteoarthritis of the knee in an interface musculoskeletal clinic: a stepped wedge trial. Patient Educ Couns 99(4):571-577. https://doi.org/10.1016/j. pec.2015.10.011

17. Fay M, Grande SW, Donnelly K, Elwyn G (2016) Using Option Grids: steps toward shared decision-making for neonatal circumcision. Patient Educ Couns 99(2):236-242. https://doi. org/10.1016/j.pec.2015.08.025

18. Branda ME, LeBlanc A, Shah ND, Tiedje K, Ruud K, Van Houten H, Pencille L, Kurland M, Yawn B, Montori VM (2013) Shared decision making for patients with type 2 diabetes: a randomized trial in primary care. BMC Health Serv Res 13(1):301. https://doi. org/10.1186/1472-6963-13-301

19. Elwyn G, Scholl I, Tietbohl C, Mann M, Edwards AGK, Clay C, Légare F, van der Weijden T, Lewis CL, Wexler RM, Frosch DL (2013) "Many miles to go...": a systematic review of the implementation of patient decision support interventions into routine clinical practice. BMC Med Inform Decis Mak 13(Suppl. 2):14. https://doi.org/10.1186/1472-6947-13-s2-s14

20. Tsulukidze M, Grande SW, Gionfriddo MR (2015) Assessing Option Grid $^{\circledR}$ practicability and feasibility for facilitating shared decision making: an exploratory study. Patient Educ Couns 98(7):871-877. https://doi.org/10.1016/j.pec.2015.03.013

21. Greenhalgh T (2013) Option grids: an idea whose time has come? Br J Gen Pract 63(608):147. https://doi.org/10.3399/bjgp13X664 315

22. Härter M, Dirmaier J, Scholl I, Donner-Banzhoff N, Dierks ML, Eich W, Muller H, Klemperer D, Koch K, Bieber C (2017) The long way of implementing patient-centered care and shared decision making in Germany. Zeitschrift für Evidenz, Fortbildung und Qualität im Gesundheitswesen 123-124:46-51. https://doi. org/10.1016/j.zefq.2017.05.006

23. Tong A, Sainsbury P, Craig J (2007) Consolidated criteria for reporting qualitative research (COREQ): a 32-item checklist for interviews and focus groups. Int J Qual Health Care 19(6):349_ 357. https://doi.org/10.1093/intqhe/mzm042

24. Elwyn G, Lloyd A, Joseph-Williams N, Cording E, Thomson R, Durand M-A, Edwards A (2013) Option Grids: shared decision making made easier. Patient Educ Couns 90(2):207-212. https:// doi.org/10.1016/j.pec.2012.06.036

25. Elwyn G, Lloyd A, Williams NJ, Beasley A, Tomkinson A (2012) Shared decision-making in a multidisciplinary head and neck cancer team: a case study of developing Option Grids. Int J Person Centered Med 2(3):421-426. https://doi.org/10.5750/ijpcm .v2i3.262

26. Harkness $\mathbf{J}$ (2016) Translation. guidelines for best practice in cross-cultural surveys. Ann Arbor, MI, US: Survey Research Center, Institute for Social Research, University of Michigan. http://ccsg.isr.umich.edu/translation.cfm. Accessed 27 Jul 2017

27. Harkness J, Pennell B-E, Schoua-Glusberg A (2004) Survey questionnaire translation and assessment. In: Presser S, Rothgeb JM, Couper MP et al (eds) Methods for testing and evaluating survey questionnaires. Wiley, New York, pp 453-473. https://doi. org/10.1002/0471654728.ch22

28. Leitlinienprogramm Onkologie (2012) S3-Leitlinie Diagnostik, Therapie und Nachsorge des Mammakarzinoms [Interdisciplinary S3-guideline for diagnostics, treatment and aftercare of breast cancer] [German] 
29. Streiner DL, Norman GR (2008) Health measurement scales-a practical guide to their development and use, vol 4. Oxford University Press, Oxford. https://doi.org/10.1093/acprof:oso/97801 99231881.001.0001

30. Coulter A, Stilwell D, Kryworuchko J, Mullen P, Ng C, van der Weijden T (2013) A systematic development process for patient decision aids. BMC Med Inform Decis Mak 13(Suppl 2):2. https ://doi.org/10.1186/1472-6947-13-S2-S2

31. Hahlweg P, Hoffmann J, Harter M, Frosch DL, Elwyn G, Scholl I (2015) In absentia: an exploratory study of how patients are considered in multidisciplinary cancer team meetings. PLoS One 10(10):e0139921. https://doi.org/10.1371/journal.pone.0139921

32. Hahlweg P, Harter M, Nestoriuc Y, Scholl I (2017) How are decisions made in cancer care? A qualitative study using participant observation of current practice. BMJ Open 7(9):e016360. https:// doi.org/10.1136/bmjopen-2017-016360

33. Mayring P (2008) Qualitative Inhaltsanalyse [Qualitative content analysis]. Beltz, Weinheim

34. Lowery AJ, Kell MR, Glynn RW, Kerin MJ, Sweeney KJ (2012) Locoregional recurrence after breast cancer surgery: a systematic review by receptor phenotype. Breast Cancer Res Treat 133(3):831-841. https://doi.org/10.1007/s10549-011-1891-6

35. O'Brien M, Charles C, Lovrics P, Wright F, Whelan T, Simunovic M, Kennedy E, Grunfeld E (2014) Enablers and barriers to using patient decision aids in early stage breast cancer consultations: a qualitative study of surgeons' views. Implement Sci 9(1):174. https://doi.org/10.1186/s13012-014-0174-0

36. Schroy PC III, Mylvaganam S, Davidson P (2014) Provider perspectives on the utility of a colorectal cancer screening decision aid for facilitating shared decision making. Health Expect 17(1):27-35. https://doi.org/10.1111/j.1369-7625.2011.00730.x

37. Edmunds JM, Beidas RS, Kendall PC (2013) Dissemination and implementation of evidence-based practices: training and consultation as implementation strategies. Clin Psychol Publ Div Clin Psychol Am Psychol Assoc 20(2):152-165. https://doi. org/10.1111/cpsp.12031

38. Légaré F, Stacey D, Turcotte S, Cossi MJ, Kryworuchko J, Graham ID, Lyddiatt A, Politi MC, Thomson R, Elwyn G, DonnerBanzhoff $N$ (2014) Interventions for improving the adoption of shared decision making by healthcare professionals. Cochrane Database Syst Rev 9:CD006732. https://doi.org/10.1002/14651 858.cd006732.pub3

39. Scholl I, Hahlweg P, Lindig A, Bokemeyer C, Coym A, Hanken H, Müller V, Smeets R, Witzel I, Kriston L, Härter M (2018) Evaluation of a program for routine implementation of shared decisionmaking in cancer care: study protocol of a stepped wedge cluster randomized trial. Implement Sci 13(1):51. https://doi.org/10.1186/ s13012-018-0740-y 